\title{
MODELING DYNAMICITY OF WILLINGNESS TO PAY MECHANISM IN THE CASE OF SPECIAL ASSESSMENT DISTRICT
}

\author{
Deog Sang BAE (1D ${ }^{1^{* *}}$, Seok KIM (1D) $2^{2^{*}}$ \\ ${ }^{1}$ Risk Management Office, Hanwha Investment and Securities, Seoul, Republic of Korea \\ 2 Department of Railroad Infrastructure System Engineering, National University of Transportation, Ui-Wang, \\ Republic of Korea
}

Received 10 June 2019; accepted 27 January 2020

\begin{abstract}
A new public project usually provides economic benefits to property owners. In general, a delay caused by a government budget shortage proportionally reduces the future cash flow of the private developer potentially benefitted from a new public project. Based on that eventuality, this study examines a mechanism of willingness to pay, which asks private developers to voluntarily participate in sharing the budget shortage. This participation process is investigated by applying system dynamics, which demonstrate several causal loops, such as between the delay cause and the reaction of the private developer. In spite of difficulty in predicting the actual effect of this idea due to its conceptual origin, this innovative approach can contribute to real-world exigencies in two ways: the provision of background for research on the on-time completion of public projects via private developer cost-sharing participation and the illustration of an alternative that minimizes private developers' future revenue deduction caused by delays.
\end{abstract}

Keywords: system dynamics, public development delay, Net Present Value, private developer's cost sharing, financing alternatives, willingness to pay, special assessment district.

\section{Introduction}

Investment in public infrastructure has been historically regarded as an effective tool that invigorates macroeconomies because public projects employ extensive labor and resources in a short time and ultimately provide publicly accessible, hard assets for permanent use (Munnell, 1992). For instance, the U.S. government enacted several bills aimed at stimulating the economy damaged by the 2008 financial crisis, including the $\$ 787$ billion American Recovery and Reinvestment Act (Kenton, 2018). In addition, Trump's administration announced that $\$ 1$ trillion would be invested toward the maintenance and recovery of malfunctioning structures (Schoen, 2018). Previous studies confirmed that new public developments in on-time delivery essentially ensure the economic sustainability of developing nations (Hussain et al., 2018, 2017).

In spite of such importance, a delay in implementation often prevails in public projects (Ploth, 2015). Batool and Abbas (2017) argued that fiscal pressure is one of the main causes for the delay. Innovative financing mechanisms, such as public-private partnerships (PPPs), tax increment financing (TIF), Land Value Capturing (LVC), and spe- cial assessment districts (SADs), aim to resolve budget constraints for public projects while minimally damaging other fiscal programs, but their adaptability factors (Table 1) are different (Connolly \& Wall, 2016; Vadali et al., 2012). PPPs financed by the private sector correspond to the needs of developing nations, while TIF and SADs requiring firmly established jurisdiction systems are effective in developed nations.

PPPs that leverage developer resources to deliver public projects while minimizing government financial exposure have been adopted internationally (Bae et al., 2019). In return, the private sector is permitted to capture stable cash flows generated by the constructed asset for a contracted term. Build-lease-transfer (BLT) and buildoperate-transfer (BOT) are major contractual types of PPPs. All aspects are the same except for who assumes the revenue uncertainty. In a BLT, the government is responsible, but in a BOT, the private contractor is responsible, which weakens investment motivation. In order to address the issue, some BOT contracts contain a minimum revenue guarantee (MRG) clause that alleviates the degree of exposure by the public provision of a type of revenue

${ }^{*}$ Corresponding author. E-mail: kimseok@ut.ac.kr

**Incheon Public Infrastructure Investment Management Center, Incheon Institute, Incheon, Republic of Korea

Copyright (C) 2020 The Author(s). Published by VGTU Press

This is an Open Access article distributed under the terms of the Creative Commons Attribution License (https://creativecommons.org/licenses/by/4.0/), which permits unrestricted use, distribution, and reproduction in any medium, provided the original author and source are credited. 
insurance. Discord between estimated and real demand that triggers the MRG requires the exercise of taxpayer contributions.

TIF is a tool of value-capturing methods used to construct a new building by leveraging a net present value generated by the new project (Bae \& Damnjanovic, 2018a, $2018 \mathrm{~b}$ ). Its basic mechanism is that the bond proceeds solely backed by an increment in the real estate tax above a certain threshold in a designated area funds TIF projects. The repayment capability relying on the project's outcome transfers the financial risk from the government to bond holders. In return, a relatively high-risk premium of TIF bonds is required.

LVC charges a compulsory extra property tax to the landowners who are beneficiaries of the public project, and the collected funds from extra taxation will help to alleviate the financial pressure of the government (Enoch et al., 2010). Usually, public development raises property values (Bae \& Damnjanovic, 2018a). The increase provides a favorable environment for the landowners. The owners can ask for more rent fees from tenants or more loans from banks. However, the landowners are regarded as free riders. The funds to construct the public project are not from the landowners but from all taxpayers, yet only the landowners reap the benefits after the development. The LVC policy provides a medium to address such discrepancy by enabling the government to charge a tax against the uplifted value (Coleman \& Grimes, 2010). Specifically, Salon and Shewmake (2011) analyzed the connections between the price indexes of property values and newly constructed public transportation projects in East Asia and proposed the policy frameworks of taxing property value betterment. Additionally, Munoz-Gielen (2012) compared social surroundings and legal approaches between the UK, The Netherlands, and Spain in terms of introducing the new taxing mechanism by applying the conceptual networking analysis methodology.

SADs are another tool of value capturing but is voluntarily activated unlike the LVC compulsorily triggered (Mathur, 2014). The SAD mechanism is similar with TIF in utilizing economic benefits from a new development project financed by an innovative budgetary policy within a specific undeveloped zone or asset. A SAD project requires upfront economic contributions from the property owners, and they vote for the activation in the planning phase. Like LVC, taxpayers are directly exposed to project risks, while the bondholders of SADs do not bear underlying risks due to the guaranteed payment. The increased tax burden can both cause taxpayer resistance and weaken politicians' motivation (Rolon, 2008). However, in many cases, an SAD program has provided successful delivery of new infrastructure and in the process brought harmony to the community, stimulated economic prosperity, and helped relieve inequity by constraining free riders (Hoyt \& Gopal-Agge, 2007).

All four alternatives have positive and negative aspects. A PPP is suitable to capital project development and reduces project risks from the government's perspective, but it negatively impacts the national economy due to the extra cost caused by reimbursing the investment and providing profits to the private investors. The policy of charging an extra compulsory property tax derived by LVC to the beneficiaries from a public development can address the government budget shortage issue and the value discrepancy caused by unevenly distributed development benefits after the public development, but the policy has many drawbacks, such as taxpayers' resistance, betterment value quantification, and an unsuccessful history of being introduced into policy. Unlike the policy of LVC, the policy of SADs that are facilitated in voluntary participation does not cause such drawbacks.

\section{Research objectives and contributions}

This paper, by applying system dynamics, presents a dynamic model that illustrates the process of economic materialization caused by activation of the willingness to pay mechanism incorporated under a SAD program. The modeling attempt to resolve real issues by applying theoretical modeling methods is not new (Karna et al., 2009; Maqbool, 2018). Here, the key of a SAD program is voluntary payment mechanism, which can be reinstated as property owner's willingness to participate in the budget shortage issue of the public project.

The SAD's feature that requires upfront contribution from property owners transfers economic risks of a public project delivery transfers economic risks from the public entity to property owners. Such shift strengthens the criticality of determining the degree of willingness. Observing case studies provide a proxy of determining the willingness degree, but, short of the SAD history does not allow relevant data. Furthermore, the idea of simulation design of a SAD program in regarding to voluntary payment mechanism and its economic materialization has not been actively discussed. This paper, as its research objective, aims to provide a framework of predicting the actual

Table 1. Innovative financing tools

\begin{tabular}{|l|c|c|c|c|}
\hline \multicolumn{1}{|c|}{ Categories } & Taxpayers & Developer & Riders & Investors \\
\hline PPP (BOT) & - & $\sqrt{ }$ & $\sqrt{ }$ & $\sqrt{ }$ \\
\hline TIF & - & - & - & - \\
\hline LVC & $\sqrt{ }$ & - & - & - \\
\hline SAD & $\sqrt{ }$ & - & - & \\
\hline
\end{tabular}


effect of SAD program for the perspective of landowners by simulating the degree of willingness.

Under such stance, this paper contributes to the society in three ways. First, this study pioneers the subject of economic motivation accruals from the perspective of the private side, by providing background for research on the on-time completion of public projects via private developer cost-sharing participation and illustrating an alternative that minimizes private developers' future revenue deduction caused by delays. Second, the presented study model aims to provide quantitative and visualized architecture that describes causality between variables, scenarios that constitute the underlying framework of the simulation exercise. Third, this study can provide a practical solution for other public projects in that the research model is developed by reviewing a real case study in which a significant delay in a railway development project was caused by a budget shortage but was resolved by adoption of a SAD.

\section{Literature review}

\subsection{Methodology comparison}

The success of a SAD program strongly depends on the potential appreciation of real estate value. Such an environment can affordably raise interest in the adaptability of estimation methodology. This chapter explores research methodologies such as regression analyses, time series analyses, artificial intelligence, and system dynamics that are used as estimation tools. Then, the following sub-chapter presents previous applications of system dynamics. The last sub-chapter illustrates the conceptual mechanism of system dynamics in order to ensure the modeling procedure that this study adopts.

In terms of regression analyses and time series analyses, many previous studies have provided theoretical backgrounds that justify those methods being used as both an estimation tool for pricing potential land prices after development and as a causality analysis tool that principally maps connectivity between variables and assesses the power of their links (Qi \& Chang, 2011). The advantage in application simplicity has led many studies to apply these conventional tools to the subject of real estate development (Funderburg, 2019; Kane \& Weber, 2015; Weber et al., 2007). Hussain et al. (2019) also proves practicality of the regression modeling to illustrate the relationship between quality in construction industry and client satisfaction. However, in disadvantage, these conventional tools, which require strong assumptions in modeling, such as the non-multi-collinearity for regression analysis and the securement of stationarity for time series, restricts universal application (Čeh et al., 2018; Escobari et al., 2015; Kirkkaleli et al., 2017). Furthermore, the fact that those methods require extensive data in order to accurately identify a relationship pattern between variables limit their adaptability.

Computational methods based on artificial intelligence (AI), which uses continuous self-learning that promotes to improvement in estimation accuracy under no assumption of modeling, are other popular methods (Abidoye \& Chan, 2017). The validity of capturing typical but nonlinear patterns from past data and estimating the future through the application of AI has certainly been proven, as observed, for example, by the fact that "Alphago" won the "Go" game against the top-ranked human player "Sedol Lee" (Wang et al., 2016). However, AI has several disadvantages. Soffar (2019) pointed out that the complexity of implementation consumes extensive resources in money, time, and labor. The requirement of extensive data for running selflearning in AI potentially also weakens accessibility to this technology. In reality, most of the relevant datasets for real estate, such as regional GDP, resident income, and so on, are not publicized on a real-time basis. One exception is the indices of Real Estate Investment Trust (REIT) equities that are traded on the stock exchange, but it cannot represent the whole status of the real estate market.

System Dynamics, which is driven by combining multi-decision system loops, can provide accurate estimation outcomes. This tool visualizes information feedback and causality between agents (Richardson, 1991; Sterman, 2000, 2001). During World War II, Jay Forrester, at Massachusetts Institute of Technology, attempted to resolve complex problems related to the air defense system by introducing causal loops. Such attempts have become more sophisticated and practical thanks to computerization (Tang \& Vijay, 2001). A systemically visualized tool approach aims to help better understand the dynamics of complex systems. The dominant subject fit to this computer-aided method is the simulation of nonlinear and convoluted systems that other methods cannot cover (Richardson, 1991). With such an approach, Sterman (2000) argued that the identified loops provide a background to design a fully understandable system, and the newly designed system consequently gives insight into determining systemic policy alternatives. Vlachos et al. (2007) argued that the uniqueness of this adaptable system to describe dynamic systems overwhelmingly exceeds the functionality of other traditional tools that rely on linear, discrete, and point-by-point matches between attributes.

Choosing system dynamics as a main methodology is defendable because this paper's purpose is to characterize dynamic behaviors of each variable that crucially affect a $\mathrm{SAD}$ project and estimate economic materialization of the project, both of which are elements that system dynamics covers. Strong assumptions in model building, which are required in regression analyses and time series analyses, can be unfit to the socio-dynamicity. In addition, a shortage of data availability on real estate analysis expulses the applicability of AI.

\subsection{Previous applications of system dynamics}

Many previous studies have applied system dynamics to resolve social problems, including financial analytics and real estate development. For example, Hovmand and Ford (2009) formulated a system dynamics model reflecting 
violence responses between aggressors and victims and statistically analyzed the dataset resulting from the system.

In the financial field, Moxnes (1990) applied system dynamics to formulate a theoretical model to calculate the net present value of a system and included statistical uncertainty aspects in the model. Henden (1994) argued that system dynamics extends the realm of financial cash flow problems beyond traditional methods. Cui (2009) designed a conceptual system dynamics model that reflects theoretical cash flow mechanisms. This formulated model provides a background for designing causal loops between financial attributes such as revenue and cost. In addition, the model is useful to analyze the effects of applied policies. However, all three of these models are oriented to consider internal business perspectives, limiting universal applicability of these proposed models toward real problems.

In the field of real estate, Xu and Coors (2012) presented a model backed by the system dynamics approach that illustrates causalities between critical elements of urban development. They identified those critical elements by using the Analytic Hierarchy Process (AHP), which is a statistics package that surveys professional responders and delivers a weight of an individual variable against others. In addition, the system model by Hwang et al. (2013) uniquely included external and internal attributes in a single model. The fundamental causal loop of the model is the housing supply and demand relation, and the relation is controlled by the housing price. This is the internal causal loop in this model. To investigate between government policy and the reaction of the internal loop, they linked government policy to the housing price. Such formulation implies the linkage between external and internal criteria within the system.

Outcomes of previous studies convincingly argue that system dynamics has proved its practicality in understanding social problems and delivering optimal solutions, and its limitations are mostly caused by the model design steps. Thus, system dynamics-because it helps define interactions between attributes-strongly fits this study purpose that aims to resolve construction budget shortfall problems by inviting additional taxpayers' contributions. However, because of the complexity of modeling, researchers in the subject of social science have rarely used this research tool (Franco et al., 2018). In order to overcome such a challenge, this study presents the process of modeling for each step. Also, for clarification, it articulates the target problems by implementing a sub-module that exclusively contains individual agent activities. Then, it integrates each sub-module into a system in consideration of mutual interactions between agents.

\subsection{The conceptual mechanism of system dynamics}

A simulation model utilized by system dynamics is constructed by following four steps: problem articulation; feedback loop development; simulation model implementation; and model validation (Barlas, 2007; Hwang et al., 2013). The first step is to build a foundation for simulation modeling upon a clear perception of a targeted system. It defines key variables and their referencing behaviors within the system, defines interaction between elements, and defines validation methods. Next, a conceptual feedback loop is constructed by combining two aspects: causality and policies. Causality here means clearly illustrating the problem provocation courses by comprehensive review of mutual interactions between elements. One suggestion for the illustration is to draw a simple causality diagram using the key variables and then to calibrate the model's structure. A feedback loop is created if multiple causalities circulate in a closed system. Controlling a water tap to fill in a water tank within a limited time but without overflow is a typical example of a balancing feedback loop because the stocked amount in the tank governs the input volume (Figure (1a)). In the figure, the signal of positive $(+)$ and negative $(-)$ means the direction of influence. For positivity, cause and result variables change in the same direction. For negativity, these variables change in the opposite direction. Next, the simulation architecture is developed by application of the conceptual model. Figure 1(b) illustrates a simulation diagram of water tap control developed from its conceptual feedback loop. Specifically, Figure 1(b) contains two structures: stock and flow and reference mode. Stock and flow are qualities originating from the looping attributes of Figure 1(a). The reference mode, which is linked to each attribute, is a diagram that shows expected characteristic behaviors. For example, the downward direction on the water tap's reference mode indicates a decrease in water inflow. The convex feature of the water tank's reference mode shows the level of stock. Last, the model's validity is confirmed by comparison between simulated results and reference modes.

\section{Designing a conceptual model}

\subsection{Case study backgrounds}

This study investigates the motivation of people's willingness to pay an additional tax under the SAD mechanism to relieve public construction budget shortage and investigates taxpayers' economic reward for the voluntary payment by comparing asset values both inside and outside the SAD boundaries. Therefore, the Dulles Corridor Metrorail Project is presented as a case study. This new project extends the silver line of the Washington Metro system from East Falls Church to the Dulles Airport (Dulles Corridor Metrorail Project, 2019). This project consists of Phase I and II. The five stations under Phase I were opened in 2014. The total length is $30.9 \mathrm{~km}$ (Phase I-18.7 km; Phase II-18.2 km). The total capital cost is $\$ 5.8$ billion (Phase I- $\$ 3.0$ billion; Phase II- $\$ 2.8$ billion).

The necessity of this railway project has been actively discussed since 1960, but construction could not begin for decades due to lack of funding at the municipality level (Dungan, 2014; FHWA, 2018). A group known as the Landowners Economic Alliance for the Dulles Extension of Rail originated a critical initiative to fast-track 


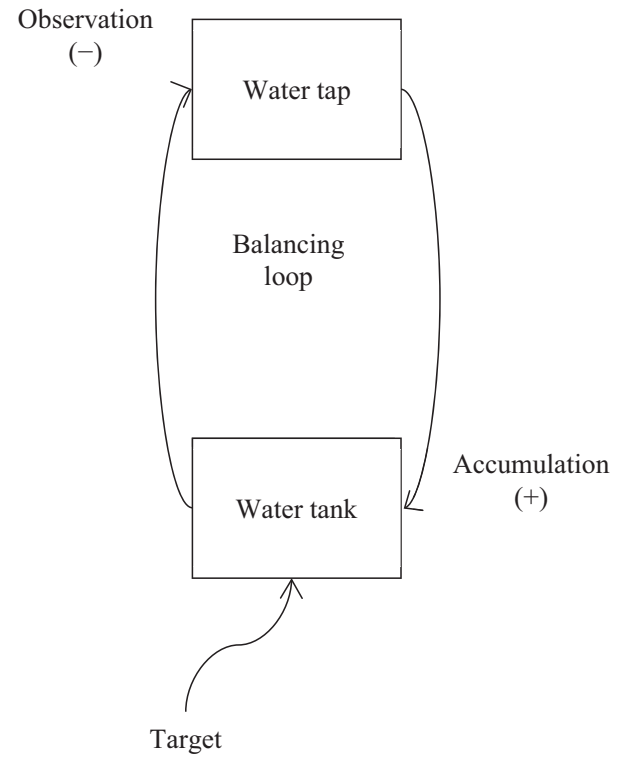

a) Conceptual feedback loop

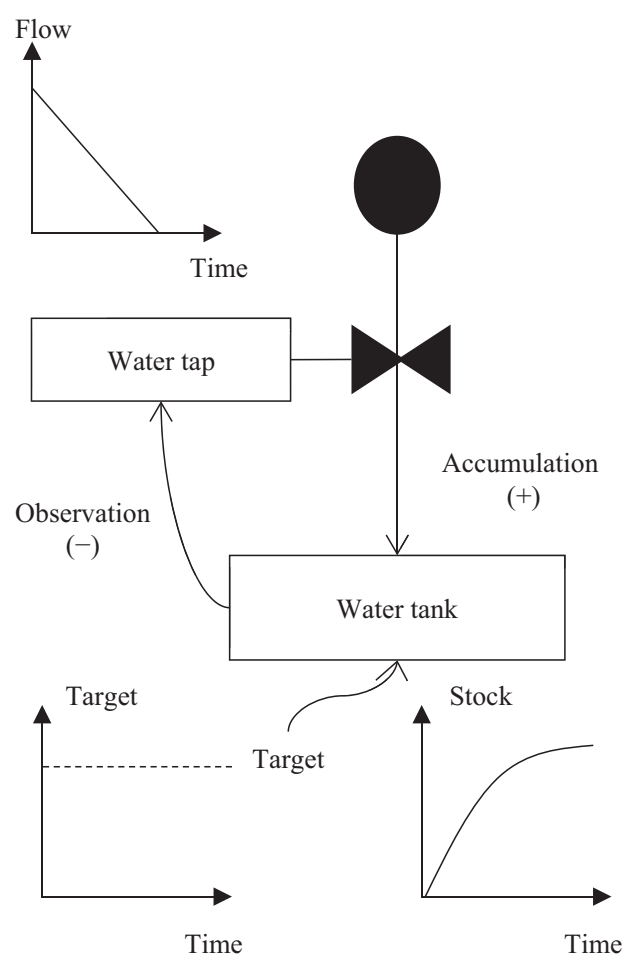

b) Simulation model

Figure 1. System dynamics

the project. The group, mainly consisting of local landlords, evaluated economic benefits associated with railway accessibility in early 1980. Next, it proposed a fiscal program in which landowners in an effective area of the new rail system pay additional taxes in order to expedite the rail delivery. The voluntary movement encouraged local and national politicians to advance the project. One critical moment occurred in 2005 when Congressman Wolf secured $\$ 30$ million. Phase I construction began in 2008 and finished in 2014, and Phase II construction began in 2014 .

In 2004, Fairfax County designated transportation improvement districts and began to increase the property tax rate to $0.22 \%$ (FHWA, 2018). Commercial and industrial landowners were the entities taxed by this program. The increased rate decreased to $0.19 \%$ in 2016 , and the taxing program is expected to end in 2019 when Phase II construction is terminated. The anticipated sum of $\$ 915$ million from the SAD will contribute $16 \%$ of the capital expense of Phase I and II. For upfront payment and financial risk transfer, the Metropolitan Washington Airports Authority issued bond proceeds of $\$ 248$ million backed by the SAD revenue. The financial strength of the local government and the strong business concentration, which contains headquarters of five Fortune 500 companies, led to an outstanding AA credit rating of these bonds (Business Wire, 2016). The SAD brought economic prosperity to the region. The assessed value of commercial and industrial properties within the SAD boundaries had ex- ponentially grown from $\$ 5$ billion in 2001 to $\$ 12$ billion in 2016, and in the same period the compounded annual growth rate was 6\% (FHWA, 2018).

Figure 2 illustrates economic changes by comparing properties located between SAD and non-SAD areas. Figure 2(a) displays the SAD boundaries around Tysons Corner. In this region, properties located in the red and purple areas have been additionally taxed. The representative structure of the taxing program is Tysons Corner Center, which is a supersized shopping mall (size of land and structure is $268,342 \mathrm{~m}^{2}$ and $147,368 \mathrm{~m}^{2}$, respectively). Jones (1445 Chain Bridge Rd) and Leesburg (7501 Leesburg Pike) are selected, which are also shopping malls but smaller in size, are selected for comparison. Figure 2(b) shows the value trends of the three properties, described as the cumulative growth rate from the base year of 2001 . Up to 2004, all three trended flat. After 2005, the trend of Tysons Corner spiked, and the upward trend has continued even while the other properties have remained static. A possible cause is that fund raising in earnest began in 2005. The groundbreaking led to a reinforcing economic loop. First, improved accessibility increased chances of visitors to the area, and second, increased revenue improved the quality and facility, and third, improvement raised the popularity of places. Jones and Leesburg have not yet secured the opportunity of overturning their business environments. Clearly, the delivery of a railway financially supported by voluntary participation is the key differential between Tysons Corner and the others. 


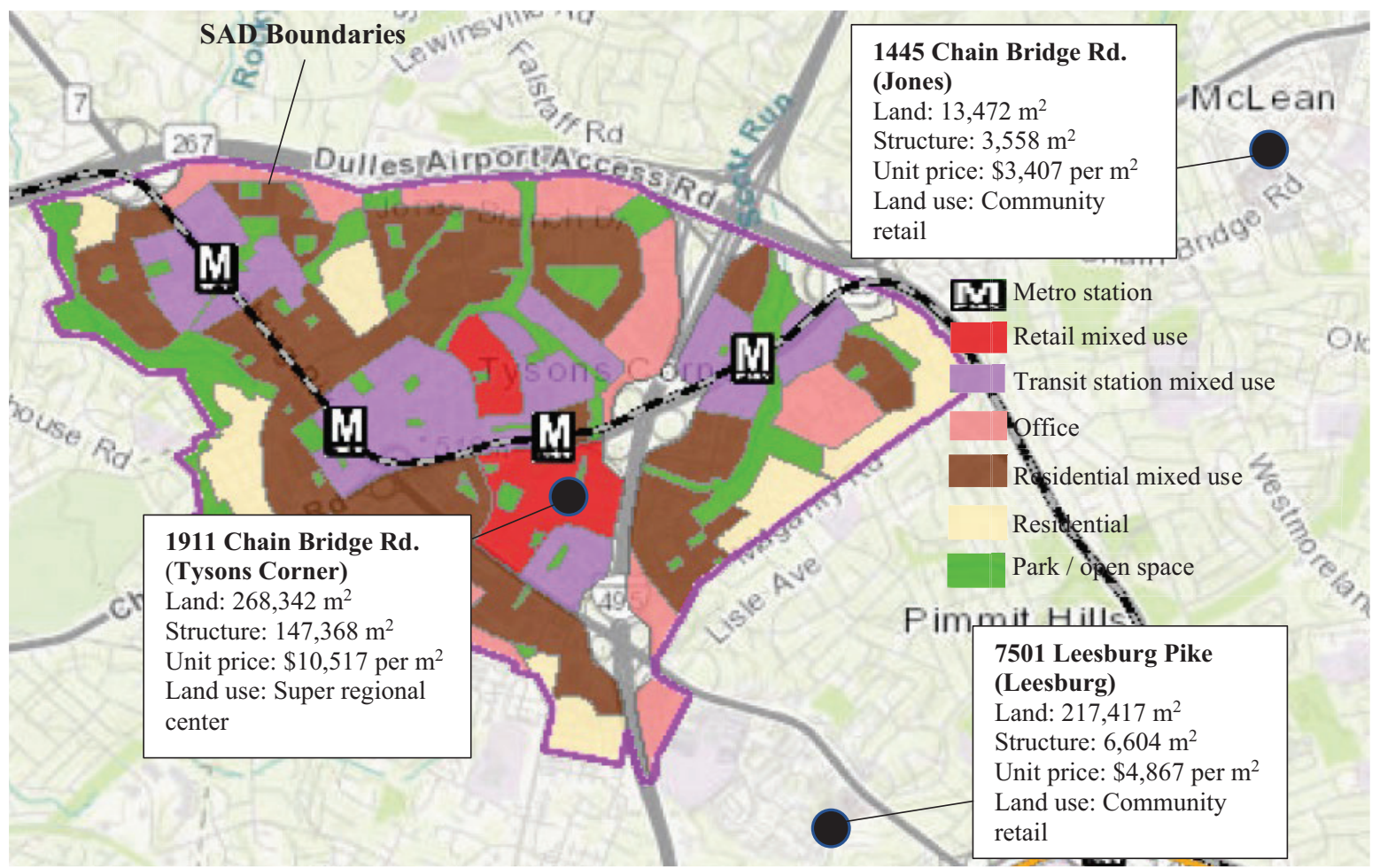

a) Neighborhood map

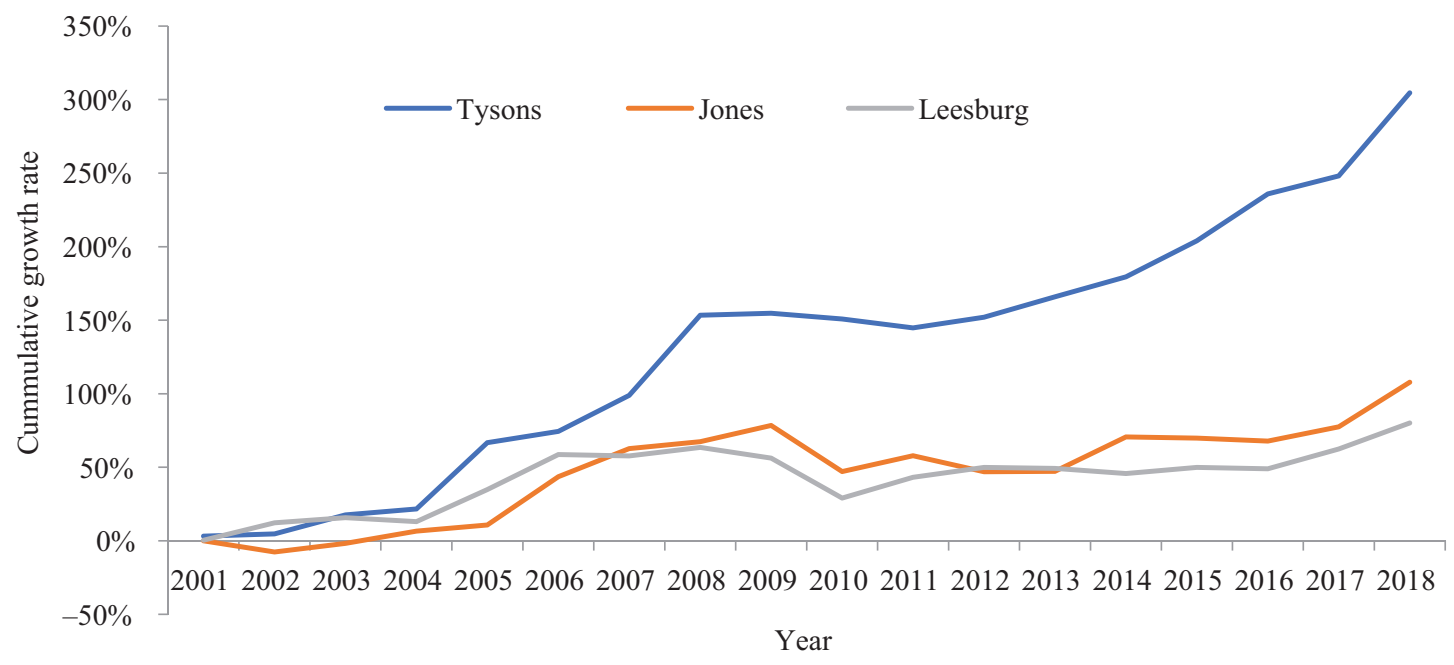

b) Value trends

Figure 2. Tysons Corner SAD

\subsection{Simulation scenario development}

The key problem in the process of SAD is to identify the rationale behind the landowners' decision to voluntarily contribute. Landowners were fully exposed to project risks; the participation conditions of the additional tax rate and charging period were predetermined before the time of railway project realization. Consequently, the landowners' payoff is determined by the difference between the fixed addition to the cost and the volatile addition to the revenue. This study aims to identify the financial mechanism of payoff generation from the perspective of the private owners by following the system dynamics formulation steps.
The key problem can be reconstituted to key variables and their behaviors. This study defines revenue and operating expenses, as the critical component. Then, such critical parts are presumed to be linked to sub key variables. Revenue is mainly influenced by inflation, budget completion effect, and operating expenses by maintenance cost, property tax, voluntary tax payment, and credit revolving facility (Table 2). After the variable definition, this study develops three simulation scenarios-baseline, small, and large (Table 2). The baseline is the AS-IS status of not being involved with the program. The small and large scenarios are involved in the program but are distinguished according to the level of participation. 
Table 2. Scenario development

\begin{tabular}{|l|c|c|c|c|}
\hline \multicolumn{2}{|c|}{ Category } & AS-IS & Small contribution & Large contribution \\
\hline \multirow{2}{*}{ Revenue } & Inflation & Applied & Applied & Applied \\
\cline { 2 - 5 } & Budget completion effect & None & Since 5th year & Since 3rd year \\
\hline \multirow{3}{*}{$\begin{array}{l}\text { Operating } \\
\text { expenses }\end{array}$} & Maintenance cost & Applied & Applied & Applied \\
\cline { 2 - 5 } & Property tax & Applied & Applied & Endied at 5th year \\
\cline { 2 - 5 } & Voluntary tax payment & None & End at 3rd year & Repayment begun since 5th year \\
\cline { 2 - 5 } & Credit revolving facility & None & Repayment begun since 3rd year & \\
\hline
\end{tabular}

a) Revenue

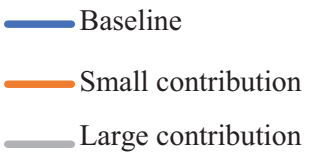

Trigger for small contribution

Trigger for large
contribution

12

2

b) Operating expenses

c) Operating profit

d) Credit revolving facility

e) Accumulated dividends

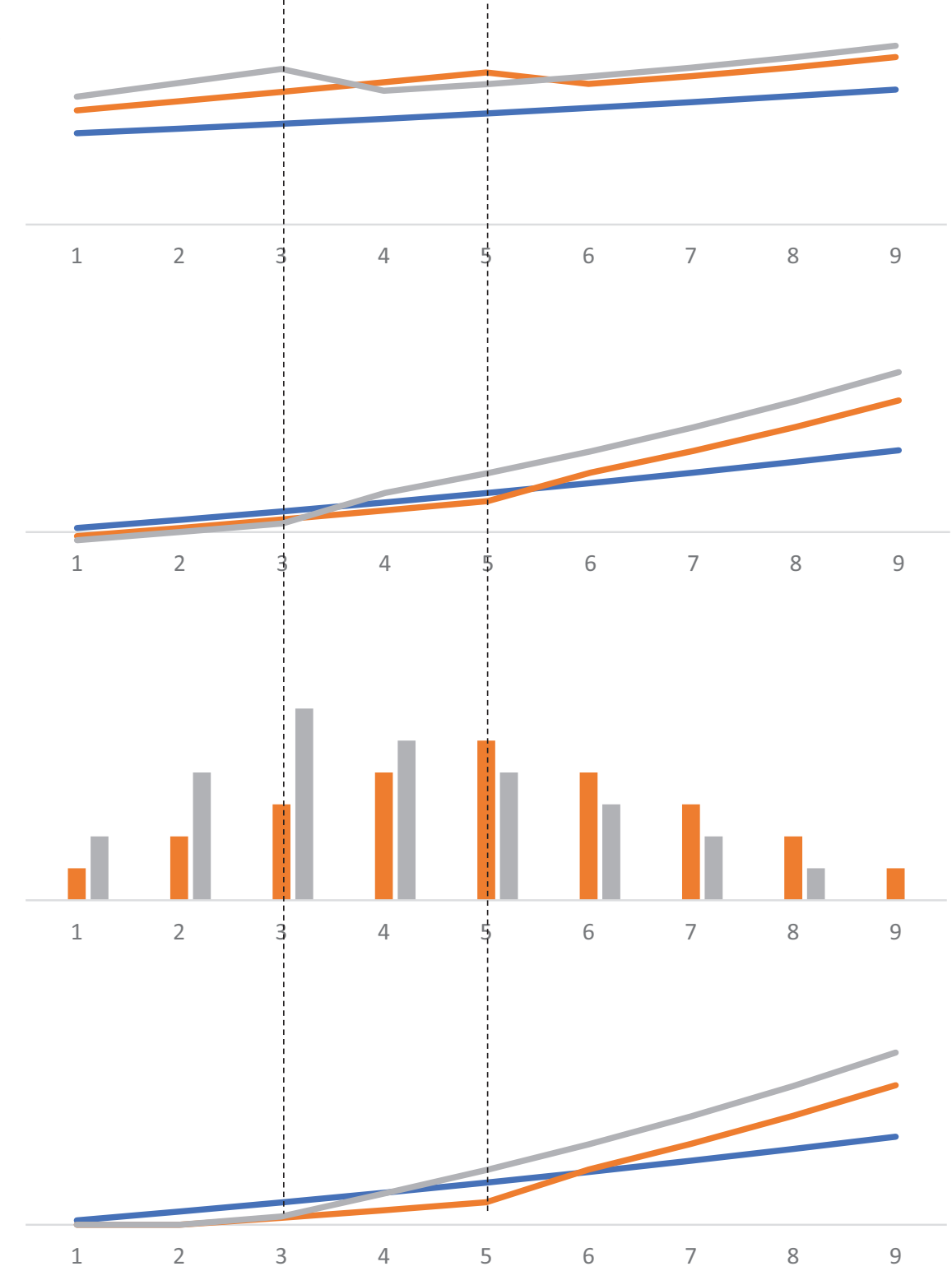

Figure 3. Key variables and their reference modes (Y axis: monetary value; $\mathrm{X}$ axis: time) 
Next, this study hypothetically draws behaviors of each key variable (Figure 3 ) by referencing the evident behaviors of property values in regard to the voluntary tax program shown in Figure 2(b). Sterman (2000) defined a hypothetical behavior, which is defined as reference mode in system dynamics modeling, as a pattern of behavior on an unfolding time horizon that shows the system problem in a specific and understandable way to the simulation design modelers and non-affiliated bodies. In addition, the dynamics of the pattern provide insight on how each variable is related to another and on which possible policies are applicable to address problems arising from the dynamic pattern.

In this developed hypothesis, different gradients of each variable on the revenue are created under the assumption that more contribution accelerates the completion of budget securement and advances the realization of uplifted economic effects accrued by the new project (Figure 3(a)). The voluntary contribution also affects the operating expenses (Figure 3(b)). Observed sharp drops in the small scenario and in the mid-large scenario indicate the termination of the voluntary tax program due to the completion of budget securement. The diagram of the operating profit (Figure $3(c)$ ) is the result of a combination of the revenue and the operating expenses. The credit revolving facility (Figure $3(\mathrm{~d}))$ reacts if the operating profit is negative. High interest burdens accrued from accumulated revolving credits reinforce the cycle of financial devastation. The financial pressure is illustrated in Figure 3(e). At Time 4, the dividends between the mid-large and the baseline are evenly distributed, despite a higher profit for the mid-large than for the baseline. The feature of lower dividends for the small rather than the mid-large strengthens the argument that a higher contribution results in a higher benefit.

\subsection{Feedback loop}

The feedback loop has both an external and internal scope (see Figure 4). The external scope is the relation between the public project budget completion and the reaction by the property owners who voluntarily participate to alleviate the delay problem by contributing their funds toward the public project. The internal scope includes casual business elements of the property owners. Willingness (voluntary tax payments) links between the internal and external scopes. The link eventually leads to formation of two causal loops-one between property value and valuation influence and one between cash balance and revolving credits.

Basically, Willingness, which helps secure the budget for project development, positively stimulates Budget Completion and ultimately catalyzes fulfillment of the construction. Such empowerment and Inflation Rate propel Property Val$u e$ in the first causal loop, through the process of Valuation Influence. Property Value accumulatively increases over time. A revenue realized by collecting rent, which is the multiplication between Property Value and Rent Based Cap Rate (\%), contributes to positivity in Operating Profit. Meanwhile, both a voluntary payment determined by Willingness and a cost of Required Maintenance Budget proportionally expanded by an increase in Property Value negatively affect the Operating Profit through the cash of Outflow.

Cash flows between the Operating Profit in positive and the Loan Interest Payment in negative (the result of leverage for asset acquisition) are integrated inside Cash Balance. The Cash Balance is a typical loop presenting both reinforcing and balance causalities. Continuity of negative cash balances results in an exponential growth of amount inside Revolving Credits, thereby indicating a reinforcing loop. The feature that any surplus of Cash Balance immediately reacts to the accumulation in order to reduce the financial burden indicates a balancing loop.

\subsection{Stock and flow simulation design}

The conceptual diagrams of stock and flow and the link between attributes in the newly developed simulation model are developed by redesigning the predeveloped feedback loop (Figure 5). The entire model feature is contained in Figure 5(a), and subparts corresponding to

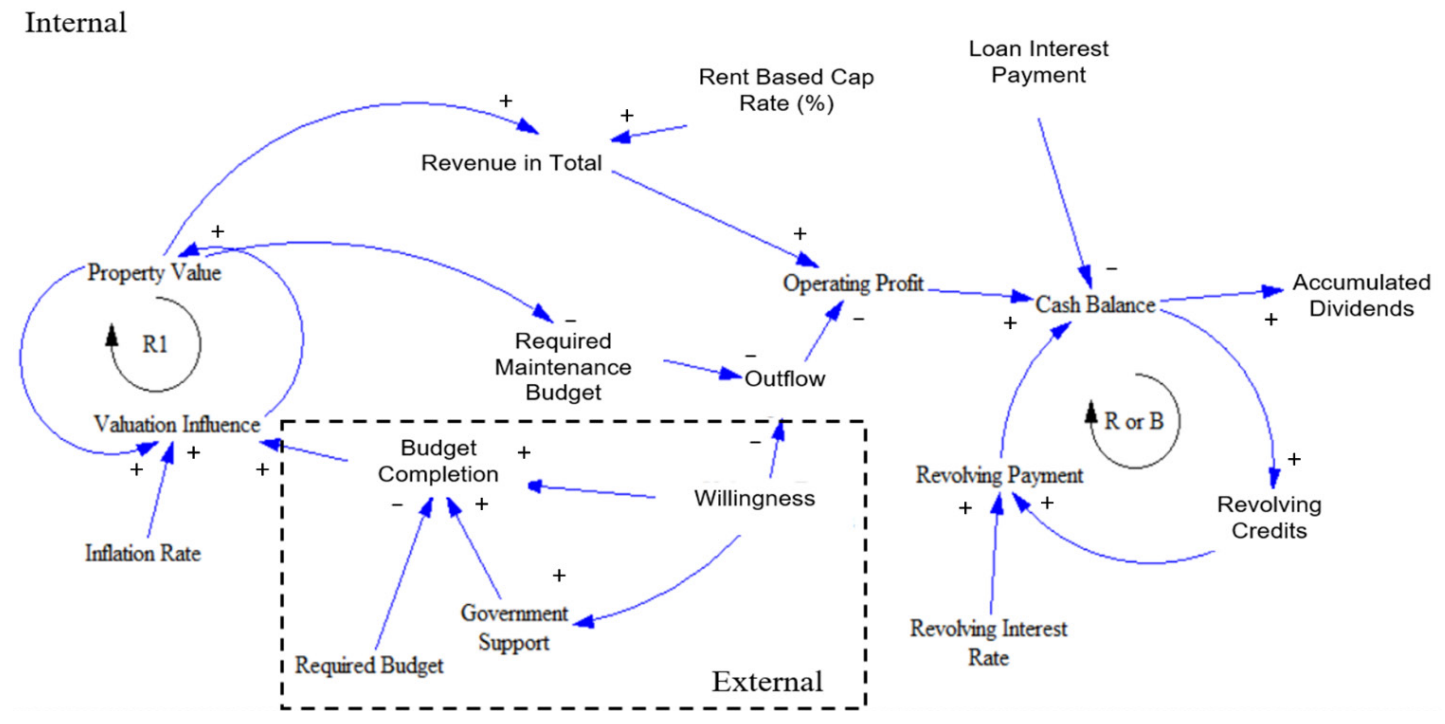

Figure 4. Feedback loop 


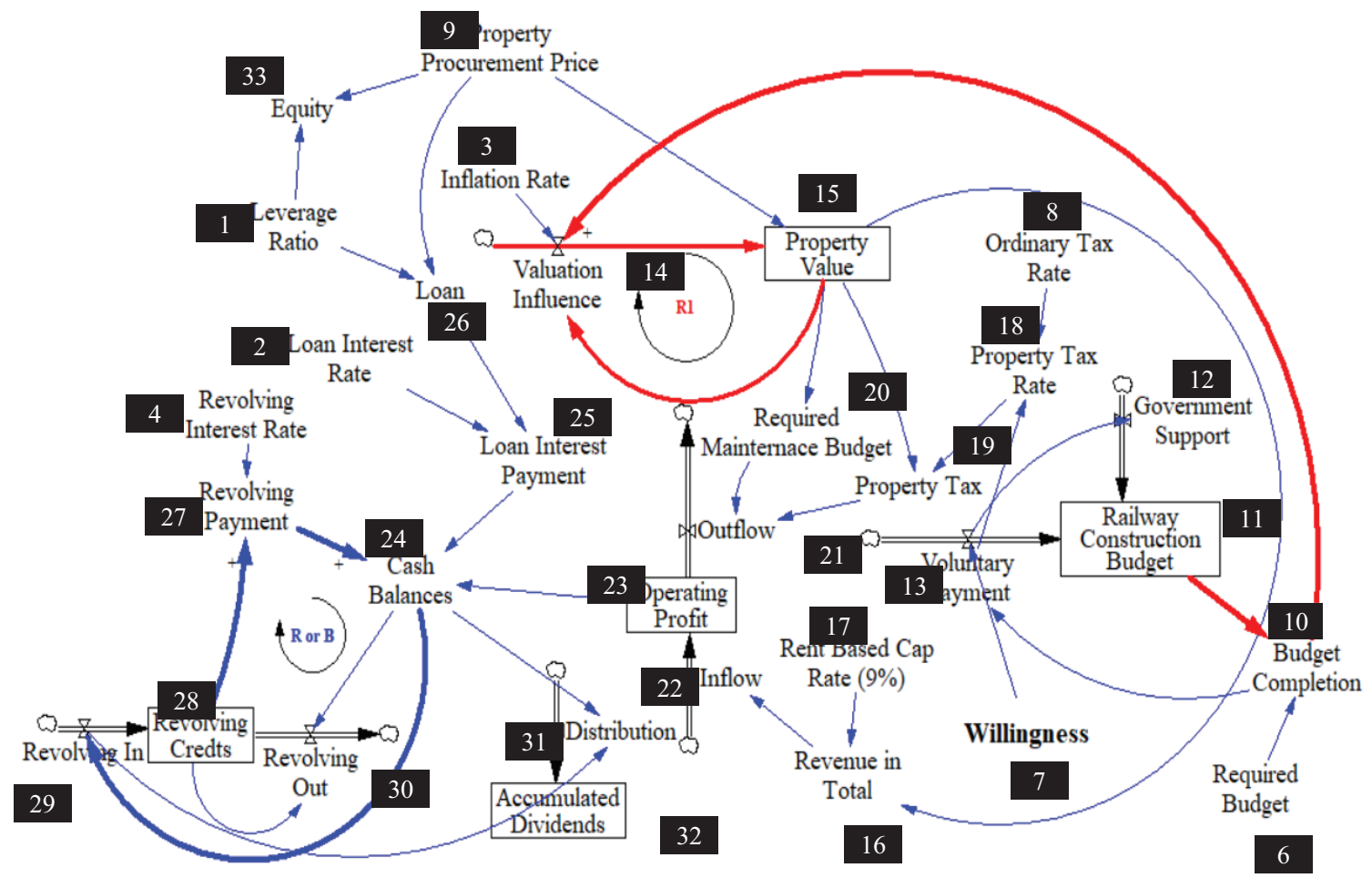

a) Simulation model outlook

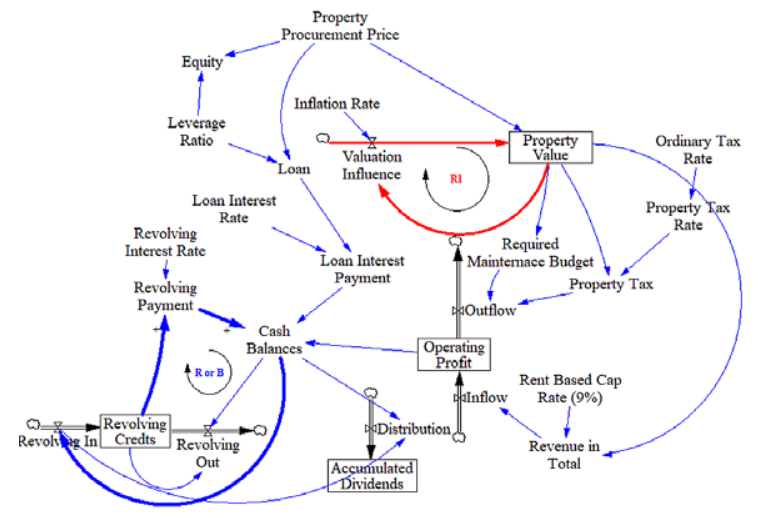

b) Internal

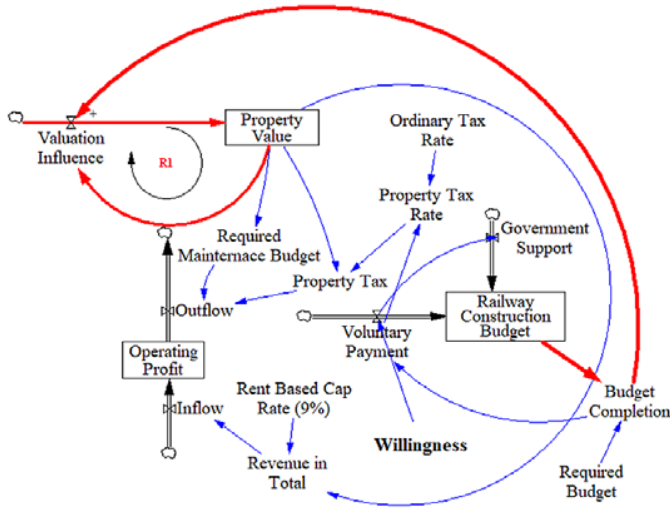

c) External

Figure 5. Simulation model

internal and external feedback loops as shown in Figure 4 are illustrated in Figure 5(b) and Figure 5(c). Each variable in Figure 5(a) is numbered, and Table 3 contains description of each variable according to the assigned number.

In specific, the key variable is Willingness, which determines the level of voluntary payment by the property owner to the public project. If Willingness is greater than zero, a new property tax rate, created by the sum between the ordinary tax rate and the willingness, is charged to the property owner. Meanwhile, the construction budget sourced from the private body accumulates. The effect of Budget Completion, triggered if the accumulated budget satisfies the required budget, provides an additional increase in Property Value through Valuation Influence process.
Valuation Influence critically links between the conventional influence by Inflation Rate and the unconventional power assumed as of $5 \%$. The unconventional impact is triggered if $67 \%$ of Required Budget is secured. The figure of 0.033 on Required Budget is determined by simple calculation using the available information (FHWA, 2018): SAD tax rate $(0.22 \%$ /year $) \times$ effective taxation period $(15$ years). The underlying assumption is that the private sector's budget accumulation ensures that the public side will proportionally fund the rest of the project budget. In other words, at the time of budget completion, the public and private sides simultaneously accomplish 100\% their goals. The core concept of the SAD policy that enables fast delivery of a public project with aid from the private 
Table 3. Key variable definitions

\begin{tabular}{|c|c|c|c|}
\hline No & Key variables & Description & Type \\
\hline 1 & Leverage ratio & Static $70 \%$ assumed & Aux \\
\hline 2 & Loan interest rate & Static $6 \%$ assumed & Aux \\
\hline 3 & Inflation & Static $2 \%$ assumed & Aux \\
\hline 4 & Revolving interest rate & Static $10 \%$ assumed & Aux \\
\hline 5 & Rent based cap rate & Static $9 \%$ assumed & Aux \\
\hline 6 & Required budget & $0.033(0.22 \% /$ year $\times 15$ years $)$ & Aux \\
\hline 7 & Willingness & Driven according to simulation scenarios & Aux \\
\hline 8 & Ordinary tax rate & 0.01275 (The property tax rate in that region) & Aux \\
\hline 9 & Property procurement price & Static 100 assumed & Aux \\
\hline 10 & Budget completion (\%) & Railway construction budget/Required budget & Flow \\
\hline 11 & Railway construction budget & $\int_{0}^{t}($ Government support + Voluntary payment $) d t$ & Stock \\
\hline 12 & Government support & $\begin{array}{l}\text { Voluntary payment } \times 0 \\
\text { (Government support excluded) }\end{array}$ & Flow \\
\hline 13 & Voluntary payment & $\begin{array}{l}\text { IF (Railway construction budget>Required budget), True: } 0 \text {, } \\
\text { False: Min (Willingness, Required budget-Railway construction budget) }\end{array}$ & Aux \\
\hline 14 & Valuation influence & $\begin{array}{l}\text { IF: Budget completion }>=0.67 \\
\text { True: Property value } \times\left[0.05^{\star}+\text { Inflation rate }+\operatorname{STEP}(-0.05,15)^{\star *}\right] \\
\text { False: Property value } \times \text { Inflation rate } \\
{ }^{*} 0.05(5 \%) \text { is additional growth rate } \\
{ }_{* *} \text { STEP is the function that limits the } 5 \% \text { growth rate until } 15^{\text {th }}\end{array}$ & Flow \\
\hline 15 & Property value & $\int_{0}^{t}($ Valuationinfluence + Property procurement price $) d t$ & Stock \\
\hline 16 & Revenue in total & Property value $\times$ Rent based cap rate & Flow \\
\hline 17 & Rent based cap rate & 0.09 & Aux \\
\hline 18 & Property tax rate & Ordinary tax rate + Voluntary payment & Flow \\
\hline 19 & Property tax & Property value $\times$ Property tax rate & Flow \\
\hline 20 & Required maintenance budget & Property value $\times 0.03$ & Flow \\
\hline 21 & Outflow & Property tax + Required maintenance budget & Flow \\
\hline 22 & Inflow & Revenue in total & Flow \\
\hline 23 & Operating profit & Inflow - Outflow & Flow \\
\hline 24 & Cash balances & Operating profit - Loan interest payment - Revolving payment & Flow \\
\hline 25 & Loan interest payment & Loan $\times$ Loan interest rate & Flow \\
\hline 26 & Loan & Leverage ratio $\times$ Property procurement price & Flow \\
\hline 27 & Revolving payment & Revolving credits $\times$ Revolving interest rate & Flow \\
\hline 28 & Revolving credits & $\int_{0}^{t}($ Revolving In-Revolving Out $) d t$ & Stock \\
\hline 29 & Revolving in & $\begin{array}{l}\text { IF: Cash balances }<0 \\
\text { True: Cash balances } \times-1 \text {, False: } 0\end{array}$ & Flow \\
\hline 30 & Revolving out & $\begin{array}{l}\text { IF: Revolving credits }>0 \text { and Cash balances }>0 \\
\text { True: MIN (Cash balances, Revolving credits), False: } 0\end{array}$ & Flow \\
\hline 31 & Distribution & $\begin{array}{l}\text { Cash balances + Revolving in } \\
\text { (Negative cash balances are offset by Revolving in) }\end{array}$ & Flow \\
\hline 32 & Accumulated dividends & $\int_{0}^{t}($ Distribution $) d t$ & Stock \\
\hline 33 & Equity & $(1-$ Leverage ratio $) \times$ Property procurement price & Flow \\
\hline
\end{tabular}


side's contribution strengthens the acceptability of this assumption. In addition, five percent impact, can be justified from a real practice that five percent average difference in the annual property value growth, between Tysons Corner and other sites from 2005 to the current time (Figure 2(b)), had been shown.

In terms of Operating Profit, Revenue in Total, is calculated from rent accrued by multiplication between Rent-Based Cap Rate and Property Value. Capitalization rate (Rent-Based Cap Rate), published by global real estate agencies, is the most popular market indicator, and it shows the rate of return expected to be accrued on a real asset (Chen, 2018). The trend of the cap rate changes over time depending on the economic cycle, but for simplicity this study assumes that a certain percentage of cap rate is maintained over the course of the simulation. CBRE reported that the nationwide retail market's cap rate in the second quarter of 2018 is $8.42 \%$ (CBRE, 2018). Outflow of Operating Profit is the sum of Required Maintenance Budget and Property Tax. The annual maintenance cost is assumed of 3\% of the property value by following market practices. Charged Property Tax Rate contains two origins: Ordinary Tax Rate, which is a fundamental charge and Voluntary Payment, which is caused by Willingness.

Cash balance is mathematically calculated by deducting the operation profit from the loan interest payment and revolving payment. A surplus in cash balance is distributed in Accumulated Dividends. Otherwise, a deficit requires activation of Revolving Credit, which is a financial instrument used to resolve deficits in operating profit and eventually prevents credit events but requires a higher interest, and does not incur Distribution of dividend.

\section{Discussion}

\subsection{Simulation outcomes}

The property owner's willingness to participate in the budget shortage issue of the public project is the key variable in this research model. If the willingness is zero, the private developer will not participate in the public project, and the cash flow of the developer will be identical to the cash flow of a conventional private project. If the willingness is over zero, the private developer will participate in the public project by providing a proportionate budget to address the shortage issue. To reflect these circumstances, three simulation alternatives are executed: (1) no contribution-baseline; (2) $0.22 \%$ of the property value contribution currently applied to the voluntary program tax rate; and (3) $1 \%$ of the property value contribution to the hypothetically developed scenario. These three scenarios are identical except for the level of willingness.

Similarity between most of the simulated curves and the reference mode ideally justifies the validity of the developed model (Figure 3 and Figure 6). For example, a premise that mid-large contribution to the project yields the highest income is realized in the simulation result showing that the highest voluntary contribution generates the highest accumulated dividends (Figure 6(f)).

The main cause of difference between the non- and certain-payment is that a new public project facilitated by an additional tax accurately increases the property value directly impacted by the project. An observed gap between SAD and non-SAD property values in the real case strengthens such findings (Figure 2). The revolving credit (Figure 6(e)) and higher interest burden activated by negative cash balances causes a zero-accrued dividend for the added $1 \%$ curve in the beginning (Figure 6(f)). The negativity is caused by a sharp increase in operating expenses affected by a voluntary tax payment (Figure 6(b)). Meanwhile, the public construction catalyzed by the voluntary program increases the property value (Figure 6(a)).

Specifically, Figure 6(a) shows that the revenue of $1 \%$ causes a spike, and the uplifted effect stops at the 15th year. The stop moment is guided by the modeling assumption (Table 2). The revenue curve of the added $0.25 \%$ is later upshifted and stabilized at the 15th year. Figure 6(b) shows the operating expenses of the three scenarios. The curve of no payment shows no variance. A small addition of $0.22 \%$ added to the baseline also displays little variance in the beginning, but the property value increase triggered by budget completion causes more operating expenses charged by a proportion of the current property value. The $1 \%$ added curve shows a pattern of high, drop, increase, and then stabilized. The high burden of additional taxation causes a high expense in the beginning. The fulfillment of the tax burden leads to a drop of expense. Then, the influence of the new railway project increases both property value and operating expenses. Last, after termination of the railway effect, the operating expense increase is limited to the inflation rate. The cash balances (Figure 6(d)) are derived by combining operating profit (revenue-operating expenses; Figure 6(c)) and a loan interest payment that charges an interest cost of the long-term loan used for the asset acquisition financing. Negative cash flows observed in the curve of the added $1 \%$ caused by the additional tax payment leads to activation of the revolving credit facility (Figure 6(e)). The cash flow surplus triggered by the new public project downsizes the balance in the revolving account. Meanwhile, the available cash enables dividend distribution, which was not feasible in the beginning. The early start of the property value increase leads to the highest dividend's size of $0.25 \%$ added in the end.

In conclusion, however, an investment to the unforeseeable event without guarantee is barely processed. The feature that an insufficient increase of the property leads to financial loss to the owners can drive them to keep their current business position. As such, the people's choice of an additional $0.22 \%$ rather than an additional $1 \%$ is acceptable. Despite the smaller income, an added 0.22\% does not incur negative cash flow. 


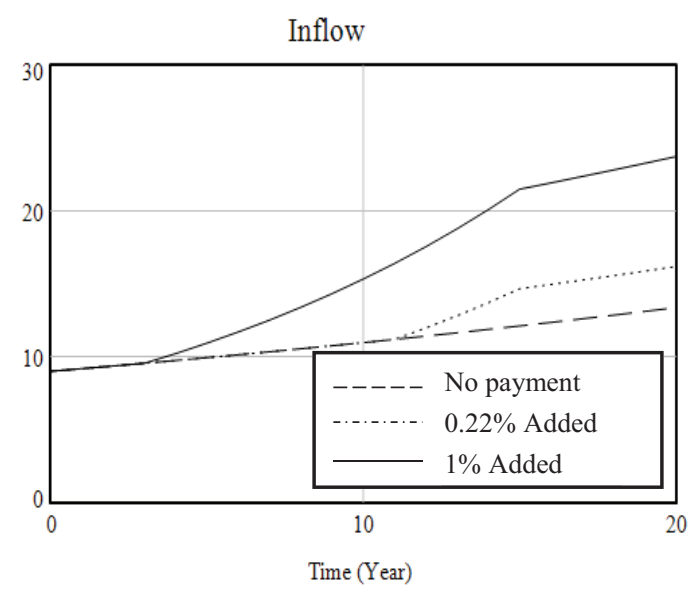

a) Revenue

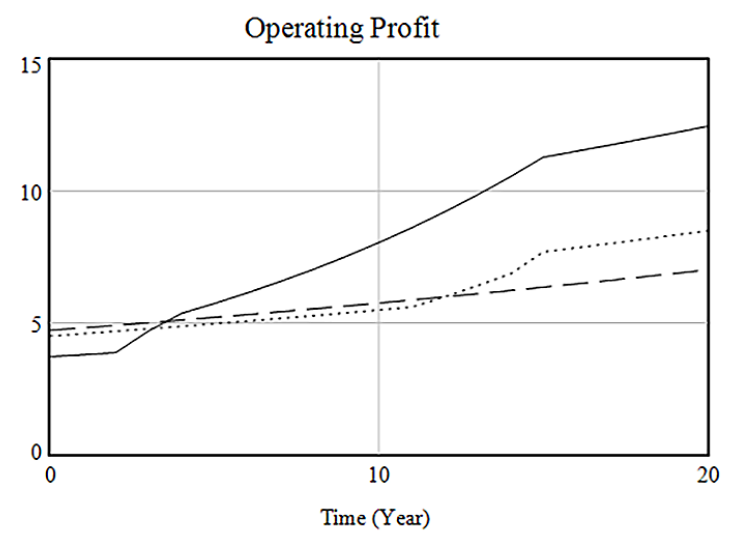

c) Operating profit

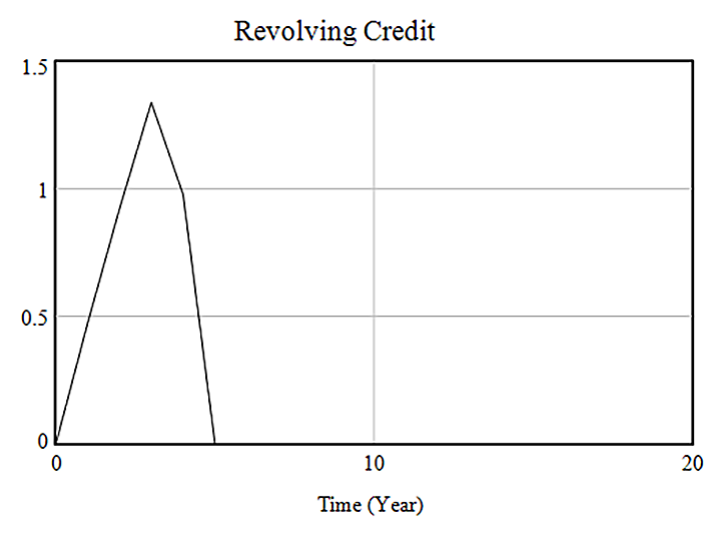

e) Revolving credit

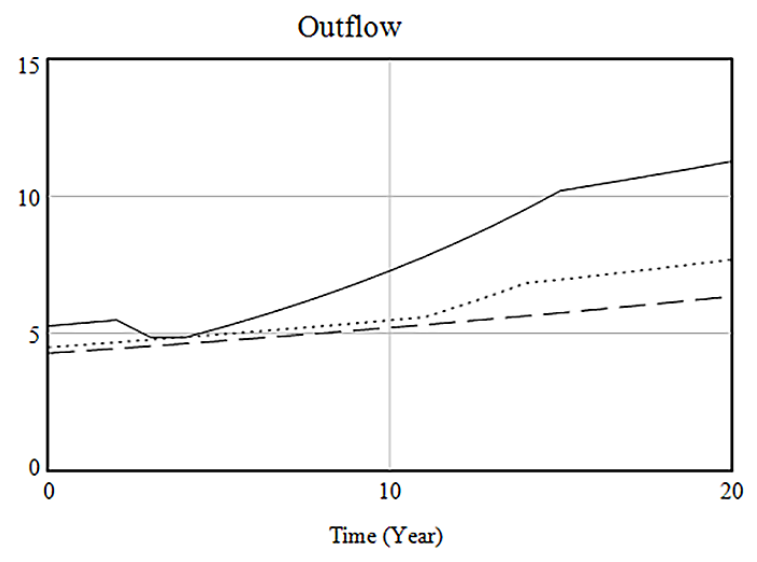

b) Operating expenses

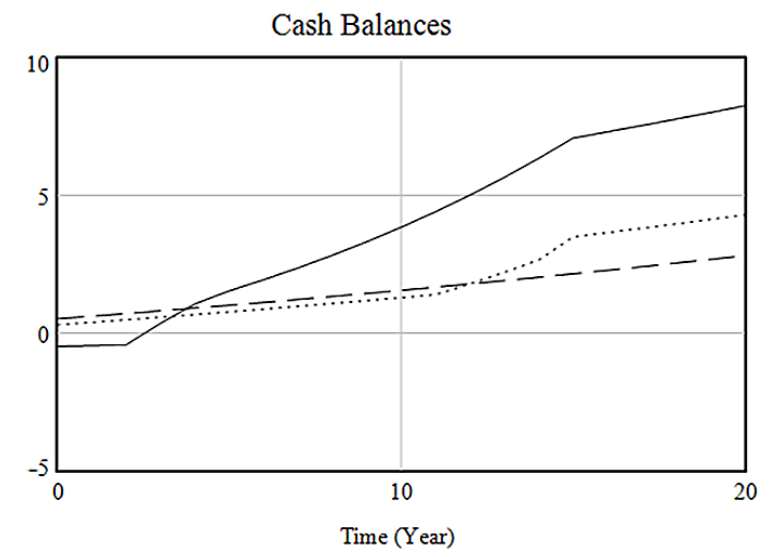

d) Cash balances

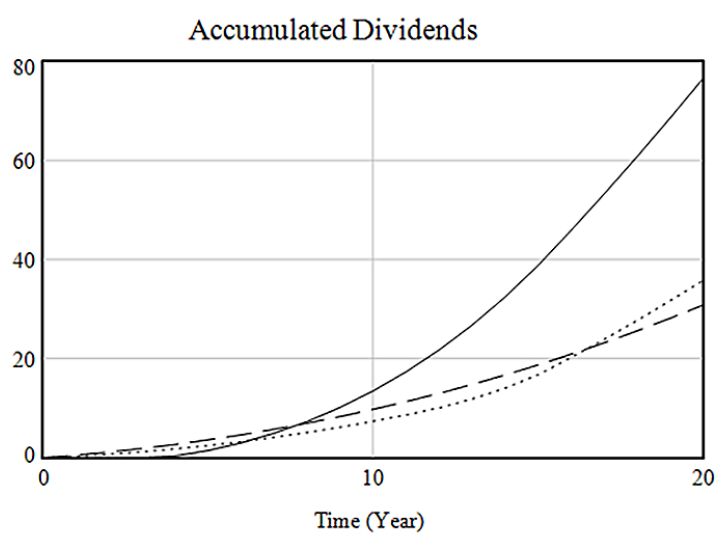

f) Accumulated dividends

Figure 6. Simulation validation (X axis: time; $\mathrm{Y}$ axis: value) 


\subsection{System dynamics applicability toward real practice}

The framework of a SAD program, which funds a new project by collecting a voluntary tax from beneficiary property owners, has resolved many issues arising from a shortage in the construction budget. The feature of an upfront payment by the property owners as an initiative to resolve the budget issue highlights the essentiality of an accurate estimation of property value increments affected by the new development. This paper attempts to illustrate the process of economic materialization in terms of the owners by using system dynamics. The validity of the study model is confirmed after determining that the simulation outcome corresponds to a real practice, but such an outcome may face two limitations in modeling implementation.

First, the coverage of a system dynamics model highly depends on the professional capabilities of modelers, and the developed model cannot fully reflect all dynamicity. The first priority in model development is to define key variables around the target issue. Leakage of variables and illogical approaches in variable definition, caused by unprofessional work or occurrence of exceptional events, critically affects the reliability of the designed system. In addition, the complexity in model development can worsen the flexibility of the model application. Value assignment in each variable is easily modifiable, but a change of system configuration can result in unexpected errors due to numerous connections between variables. Such issues can negatively affect the quality of this study's model of SAD. More discussions around system dynamics application on the subject of SAD are essential in order to strengthen the adaptability of this study into real practice.

Second, system dynamics, unlike machine learning, cannot directly deliver creative insight for problem resolution. Features such as causality between variables, variable type, and a value assigned at the beginning of simulation need to be defined ahead in order to design a model and activate the simulation. Many conventional methods, such as regression and time series, are good methods to define the causality. Such dependence on the conventional methods can raise criticism about the uniqueness of system dynamics. However, the above claim does not apply to this study. The presented model is intentionally developed to illustrate the process of economic materialization rather than to estimate future property value. Functionalities of visualization provided by the simulation can clearly describe the decision process and economic impact. These graphical approaches, which are not delivered by conventional approaches, can indirectly provide insight into developing solutions to the problem.

However, the study's theoretically oriented model can assist in finding a solution in real practice. The simulation model finds that an upfront economic contribution by the property owners results in a better outcome at the end than remaining in the current condition with no contri- bution. Such result can be understood reasonably under empirical knowledge. In a long-term perspective, intrinsic feature transformation, caused by an improvement in transportation accessibility, has been observed as a critical variable to real estate valuation. The systemic approaches shared in this study can provide a convenient ground in executing feasibility study of a project development with consuming less resources in time and money than the current environment.

\section{Conclusions}

Attempts to combine landowners' desire to improve their property values with incorporating their participation in public projects is not new. A public innovational financing scheme currently represented by SADs helps to materialize the process. This value-capturing method facilitates securing the budget as scheduled and helps lessen public development delay issues. Previous studies have actively discussed theoretical backgrounds and the practicality of the SAD program and have contributed to the implementation of more advanced mechanisms in terms of the equity in public capital distribution. This study, which has designed a newly simulated model that incorporates the power of a new public construction delivery into the conventional business framework, pioneers an approach based on the economic motivation of voluntary tax program participants.

The formulated model confirms that participation by property owners provides an opportunity to maximize their revenues in regard to accumulated dividends. This newly designed model provides stimulus to discuss the introduction of cost sharing by taxpayers to public projects, especially if the public projects influence private developers' cash flows. Cost sharing by private investors can promote punctual completion of the public projects, and furthermore, this punctuality will provide economic benefits to both private owners and local economies.

In terms of generalizability, such development helps find an optimal solution in the set of financing alternatives. Each project's uniqueness prevents universally applying a standard platform, but the core feature of the decision-making process, which values the project's economic viability by referencing real practices and assumptions, does not vary case by case. In other words, diverse characteristics of each public project may prevail applying the standalone simulation model that this study proposes, but the similarity of cashflow interaction regardless of projects, in terms of economic contribution and materialization for the perspective of property owners, ensures generalizability of the proposed simulation. The proposed simulation platform provides easy access to both policymakers and property owners in gauging the degree of project outcomes that are realized by the degree of an upfront payment determined by the willingness to pay. The users easily estimate the project's prospect by simply adjusting input parameters. 
However, insufficient public data related to SAD programs negatively affects the applicability of the proposed model. The fact that this study develops the model by using a single case can weaken attesting universal applicability of the proposed platform. Therefore, it is expected that the next study addresses this issue by compiling and analyzing multiple case studies.

\section{References}

Abidoye, R., \& Chan, A. (2017). Artificial neural network in property valuation: application framework and research trend. Property Management, 35(5), 554-571.

https://doi.org/10.1108/PM-06-2016-0027

Bae, D. S., \& Damnjanovic, I. (2018a). Credit risk assessment and monitoring of TIF bonds. The Journal of Structured Finance, 23(4), 57-68. https://doi.org/10.3905/jsf.2018.2018.1.062

Bae, D. S., \& Damnjanovic, I. (2018b). Practical applications of credit risk assessment and monitoring of TIF bonds. Practical Applications, 6(2), 1-6. https://doi.org/10.3905/pa.6.2.285

Bae, D. S., Damnjanovic, I., \& Kang, D. H. (2019). PPP renegotiation framework based on equivalent NPV constraint in the case of BOT project: Incheon Airport highway, South Korea. KSCE Journal of Civil Engineering, 23(4), 1473-1483. https://doi.org/10.1007/s12205-019-1444-9

Barlas, Y. (2007). System dynamics: Ystemic feedback modeling for policy analysis. http://www.friends-partners.org/utsumi/ Global_University/Global\%20University\%20System/List\%20 Distributions/2011/MTI2233_20110311/SYSTEM\%20 DYNAMICS_\%20SYSTEMIC\%20FEEDBACK\%20MODELING\%20FOR\%20POLICY\%20ANALYSIS\%20copy/SYSTEM\%20DYNAMICS_\%20SYSTEMIC\%20FEEDBACK\%20 MODELING\%20FOR\%20POLICY\%20ANALYSIS.pdf

Batool, A., \& Abbas, F. (2017). Reasons for delay in selected hydro-power projects in Khyber Pakhtunkhwa (KPK), Pakistan. Renewable and Sustainable Energy Reviews, 73, 196-204. https://doi.org/10.1016/j.rser.2017.01.040

Business Wire. (2016). Fitch Rates Fairfax County, VA Econ. Dev. Auth. Revs 'AA'; Outlook Stable. https://www.businesswire. com/news/home/20160219006017/en/Fitch-Rates-FairfaxCounty-VA-Econ.-Dev

CBRE. (2018). CBRE North America cap rate survey: second half 2018. http://cbre.vo.llnwd.net/grgservices/secure/North\%20 America\%20Cap\%20Rate\%20Survey_H2\%202018_s.pdf?e= 1592906262\&h=a8e0fa89b43b9fed02c90721204eb983

Chen, J. (2018). Capitalization rate. https://www.investopedia. com/terms/c/capitalizationrate.asp

Coleman, A., \& Grimes, A. (2010). Betterment taxes, capital gains and benefit cost ratios. Economics Letters, 109(1), 54-56. https://doi.org/10.1016/j.econlet.2010.08.012

Connolly, C., \& Wall, A. (2016). Value capture: a valid means of funding PPPs? Financial Accontability \& Management, 32(2), 157-178. https://doi.org/10.1111/faam.12083

Cui, Q. (2009). Systems analysis of project cash flow management strategies. Construction Management and Economics, 28(4), 361-376. https://doi.org/10.1080/01446191003702484

Čeh, M., Kilibarda, M., Lisec, A., \& Bajat, B. (2018). Estimating the performance of random forest versus multiple regression for predicting prices of the apartments. International Journal of Geo-Information, 7(5), 168.

https://doi.org/10.3390/ijgi7050168

Dulles Corridor Metrorail Project. (2019). Funding. http://www. dullesmetro.com/about-dulles-rail/funding/
Dungan, P. (2014). The Silver Line story: a new route is born after decades of faulty planning, political paralysis. https://www.washingtonpost.com/local/trafficandcommuting/ the-silver-line-story-a-new-route-is-born-after-decades-offaulty-planning-political-paralysis/2014/06/23/bdf619c4-f89411e3-a606-946fd632f9f1_story.html?utm_term=.cc7cd6e0a595

Enoch, M., Potter, S., \& Ison, S. (2010). A strategic approach to financing public transport through property values. Public Money \& Management, 25(3), 147-154. https://doi.org/10.1111/j.1467-9302.2005.00467.x

Escobari, D., Damianov, D. S., \& Bello, A. (2015). A time series test to identify housing bubbles. Journal of Economics and Finance, 39(1), 136-152. https://doi.org/10.1007/s12197-013-9251-5

FHWA. (2018). Silver Line/Dulles Metrorail, Northern Virginia (Webster Rail) - B. https://www.fhwa.dot.gov/ipd/pdfs/value_ capture/webster_rail_b.pdf

Franco, E. F., Hirama, K., \& Carvalho, M. (2018). Applying system dynamics approach in software and information system projects: a mapping study. Information and Software Technology, 93, 58-73. https://doi.org/10.1016/j.infsof.2017.08.013

Funderburg, R. (2019). Regional employment and housing impacts of tax increment financing districts. Regional Studies, 53(6), 874-886. https://doi.org/10.1080/00343404.2018.1490013

Henden, K. (1994). System dynamics underwood. Paper presented at the International System Dynamics Conference.

Hovmand, P. S., \& Ford, D. N. (2009). Sequence and timing of three community interventions to domestic violence. American Journal of Community Psychology, 44(261). https://doi.org/10.1007/s10464-009-9264-6

Hoyt, L., \& Gopal-Agge, D. (2007). The business improvement district model: a balanced review of contemporary debates. Geography Compass, 1(4), 946-958. https://doi.org/10.1111/j.1749-8198.2007.00041.x

Hussain, S., Zhu, F., \& Ali, Z. (2019). Examining influence of construction projects' quality factors on client satisfaction using partial least squares structural equation modeling. Journal of Construction Engineering and Management, 145(5). https://doi.org/10.1061/(ASCE)CO.1943-7862.0001655

Hussain, S., Zhu, F., Ali, Z., Aslam, H. D., \& Husssain, A. (2018). Critical delaying factors: public sector building projects in Gilgit-Baltistan, Pakistan. Buildings, 8(1), 6. https://doi.org/10.3390/buildings8010006

Hussain, S., Zhu, F., Ali, Z., \& Xu, X. (2017). Rural residents' perception of construction project delays in Pakistan. Sustainability, 9(11), 2108. https://doi.org/10.3390/su9112108

Hwang, S., Park, M., \& Lee, H.-S. (2013). Dynamic analysis of the effects of mortgage-lending policies in a real estate market. Mathematical and Computer Modelling, 57(9-10), 2106-2120. https://doi.org/10.1016/j.mcm.2011.06.023

Kane, K., \& Weber, R. (2015). Municipal investment and property value appreciation in Chicago's tax increment financing districts. Journal of Planning Education and Research, 36(2), 167-181. https://doi.org/10.1177/0739456X15600034

Karna, S., Junnonen, J., \& Sorvala, V. (2009). Modelling structure of customer satisfaction with construction. Journal of Facilities Management, 7(2), 111-127.

https://doi.org/10.1108/14725960910952505

Kenton, W. (2018). American recovery and reinvestment act. Investopedia. https://www.investopedia.com/terms/a/americanrecovery-and-reinvestment-act.asp

Kirkkaleli, D., Athari, S. A., \& Ertugrul, H. M. (2017). The real estate industry in Turkey: a time series analysis. The Service Industries Journal, 1-13. https://doi.org/10.1080/02642069.2018.1444033 
Maqbool, R. (2018). Efficiency and effectiveness of factors affecting renewable energy projects; an empirical perspective. Energy, 158(1), 944-956.

https://doi.org/10.1016/j.energy.2018.06.015

Mathur, S. (2014). Funding public transportation through special assessment districts: addressing the equity concerns. Public Works Management \& Policy, 20(2), 127-145. https://doi.org/10.1177/1087724X14550252

Moxnes, E. (1990). System dynamics and decisions under uncertainty. Paper presented at the Proceedings of the International System Dynamics Conference.

Munnell, A. H. (1992). Infrastructure investment and economic growth. Journal of Economic Perspectives, 6(4), 189-198. https://doi.org/10.1257/jep.6.4.189

Munoz-Gielen, D. (2012). Urban governance, property rights, land readjustment and public value capturing. European Urban and Regional Studies, 21(1), 60-78. https://doi.org/10.1177/0969776412440543

Ploth, P. M. (2015). What's taking so long? Identifying the underlying causes of delays in planning transportation megaprojects in the United States. Journal of Planning Literature, 30(3), 282-295. https://doi.org/10.1177/0885412214566116

Qi, C., \& Chang, N.-B. (2011). System dynamics modeling for municipal water demand estimation in an urban region under uncertain economic impacts. Journal of Environmental Management, 92(6), 1628-1641.

https://doi.org/10.1016/j.jenvman.2011.01.020

Richardson, G. P. (1991). System dynamics: simulation for policy analysis from a feedback perspective. In P. A. Fishwick, \& P. A. Luker (Eds.), Qualitative simulation modelling and analysis (Vol. 5). https://doi.org/10.1007/978-1-4613-9072-5_7

Rolon, A. (2008). Evaluation of value capture mechanisms from linkage capture to special assessment districts. Transportation Research Record: Journal of the Transportation Research Boar, 2079(1), 127-135. https://doi.org/10.3141/2079-16

Salon, D., \& Shewmake, S. (2011). Opportunities for value capture to fund public transport: a comprehensive review of the literature with a focus on East Asia.

https://doi.org/10.2139/ssrn.1753302
Schoen, J. W. (2018). Trump infrastructure plan comes up $\$ 1$ trillion short of its funding goal, analysis finds. CNBC. https://www.cnbc.com/2018/02/23/trump-infrastructureplan-comes-up-1-trillion-short-analysis.html

Soffar, H. (2019). Artificial intelligence in banking advantages, disadvantages \& mobile banking services. https://www.onlinesciences.com/robotics/artificial-intelligence-in-banking-advantages-disadvantages-mobile-banking-services/

Sterman, J. D. (2000). Business dynamics: systems thinking and modeling for a complex world. McGraw-Hill Education.

Sterman, J. D. (2001). System dynamics modeling: tools for learning in a complex world. California Management Review, 43(4), 8-25. https://doi.org/10.2307/41166098

Tang, V., \& Vijay, S. (2001). System dynamics origins, development, and future prospects of a method. http://web.mit.edu/ esd.83/www/notebook/System\%20Dynamics\%20final.doc

Vadali, S., Manuel-Aldrete, R., Bujanda, A., Swapnil, S., Kuhn, B., Geiselbrecht, T., \& Tooley, S. (2012). Transportation reinvestment zone handbook (Report 0-6538 Product P1 Handbook). https://rosap.ntl.bts.gov/view/dot/20254/dot_20254_DS1.pdf

Vlachos, D., Georgiadis, P., \& Iakovou, E. (2007). A system dynamics model for dynamic capacity planning of remanufacturing in closed-loop supply chains. Computers \& Operations Research, 34(2), 367-394. https://doi.org/10.1016/j.cor.2005.03.005

Wang, F. Y., Zhang, J. J., Zheng, X., Wang, X., Yuan, Y., Dai, X., \& Yang, L. (2016). Where does AlphaGo go: from church-turing thesis to AlphaGo thesis and beyond. IEEE/CAA Journal of Automatica Sinica, 3(2), 113-120. https://doi.org/10.1109/JAS.2016.7471613

Weber, R., Bhatta, S. D., \& Merriman, D. (2007). Spillovers from tax increment financing districts: implications for housing price appreciation. Regional Science and Urban Economics, 37, 259-281. https://doi.org/10.1016/j.regsciurbeco.2006.11.003

$\mathrm{Xu}, \mathrm{Z}$., \& Coors, V. (2012). Combining system dynamics model, GIS and 3D visualization in sustainability assessment of urban residential development. Building and Environment, 47, 272-287. https://doi.org/10.1016/j.buildenv.2011.07.012 